\title{
Study of ICI Suppression Method Based on Affine Fourier Transform
}

\author{
Zengyou Sun, Xia Ling \\ Department of Information Engineering \\ Northeast Dianli University \\ Jilin, China \\ Sunzengyou@163.com,448131186@qq.com
}

\begin{abstract}
The time-frequency double selective characteristic of wireless fading channel destroys the orthogonality among subcarriers, thus generating ICI, which affects the quality of communication seriously. Starting from subcarriers, an ICI suppression scheme based on affine fourier transform was proposed to achieve data communication of high reliability, high spectrum efficiency and high capacity in high-speed wireless communication environment. The scheme was that, the signal, on the sending side, was treated with IDAFT, then the chirp type cyclic prefix was inserted into the transformed signal, after a high-speed transmission channel, the cyclic prefix of the received signal was removed and then the phase was compensated, according to the channel state, and at last, the transmission signal was recovered by DAFT. Using scattering function and the actual channel parameters, the interference power and communication performance of DAFT-OFDM system were analyzed and simulated. The simulation result shows the scheme can effectively combat ICI in time-frequency double selective channel and the proposed system can keep good communication quality in the high-speed mobile environment.
\end{abstract}

Keywords-Time-frequency double selective channel, highspeed wireless mobile communication environment, Affine Fourier Transform(AFT), Invertible Discrete Affine Fourier Transform(IDAFT), Inter-Carrier Interference (ICI) suppression scheme Introduction (Heading 1)

\section{INTRODUCTION}

In recent years, with the rapid development of traffic and mobile communications technology, travelers' demand for high speed information service and high speed mobile communication, is increasingly urgent. During the transmission, radio signal is influenced not only by propagation loss, shadow effect and multipath time-delay spread, but also Doppler frequency shift caused by high-speed mobility [1]. It is a huge challenge to communication technology to keep good network coverage and communication quality in high-speed mobile environment. Mobile communications usually use OFDM modulation transmission technology. But, when OFDM system moves fast, large carrier frequency offset, which causes serious ICI, occurs for the Doppler effect and time-varying characteristic of wireless fading channel. ICI severely damages OFDM system and affects the communication quality. At present, the eliminating algorithm for ICI is mainly conducted from three aspects. One is self-cancellation and time-domain windowed method, which is not applicable to large frequency offset. The other one is frequency offset estimation algorithm whose complexity is relatively high, and sometimes iterative computation is needed. Another is equalization algorithm, which needs proper equalization filter and has high computational complexity, and sometimes needs time-varying channel estimation. In addition, the ICI elimination method based on matrix transformation is only suitable for the situation of smaller carrier frequency offset and lower- order modulation scheme. The virtual carrier estimation-based ICI elimination method is only suitable for the situation of larger carrier frequency offset and higher-order modulation scheme. To achieve high reliability, high spectral efficiency and high capacity data communication, in consideration of the affine fourier signal, compared with sinusoidal signal, with larger Doppler tolerance and much larger signal processing gain [2], this article puts forward a kind of ICI suppression method based on the AFT, from the perspective of OFDM subcarrier[3].

\section{AFFINE FOURIER TRANSFORM AND ITS APPLICATION}

\section{A. Affine Fourier transform}

In high-speed communication environment, the channel impulse response of an OFDM symbol interval varies significantly. The orthogonality between different subcarriers is severely damaged, thus causing ICI[4]. Due to the high-speed communication channel is time-varying channel, the ideal way cannot be realized by FFT and IFFT. Generally speaking, time-varying channel has special structure and one class of time-varying channel orthogonal characteristic function is linear frequency modulation type function (chirp), as follows.

$$
\varphi_{m}(n)=1 / \sqrt{N} \cdot e^{j 2 \pi\left(c_{1} m^{2}+c_{2} n^{2}+\frac{m n}{N}\right)}
$$

The transformation using the formula (1), is called discrete affine fourier transform (DAFT). While the continuous affine fourier transform (AFT) is mapping the continuous time complex signal $\mathrm{s}(\mathrm{t})$ to continuous complex signal $\mathrm{S}(\mathrm{f})$, according to the criterion of $\mathrm{S}=$ $\mathbf{A}[\mathrm{s}]$. Both $c_{1}$ and $\mathrm{c}_{2}$ are DAFT coefficients, determined 
by channel characteristics. A represents for AFT transformation.

$$
\begin{gathered}
S(f) \\
\int_{-\infty}^{+\infty} s(t) \cdot e^{-j\left(\frac{a}{2 b} f^{2}+\frac{1}{b} f t+\frac{d}{2 b} t^{2}\right)} / \sqrt{2 \pi|b|} d t, b \neq 0 \\
\mathbf{s}=\left(s_{0}, s_{1}, \ldots, s_{N-1}\right), S=\left(S_{0}, S_{1}, \ldots, S_{N-1}\right), \text { so } \\
S=A s, A=\Lambda_{c_{2}} F \Lambda_{c_{1}} \\
\Lambda_{c}=\operatorname{diag}\left(\exp \left(-j 2 \pi c^{2}\right), n=0,1, \ldots, N-1\right) .
\end{gathered}
$$

In the affine domain, the signal $s_{n}$ can be expressed by

$$
\mathrm{S}_{\mathrm{m}}=\sum_{\mathrm{n}=0}^{\mathrm{N}-1} \mathrm{~S}_{\mathrm{n}} \varphi_{\mathrm{m}}^{*}(\mathrm{n})
$$

$\varphi_{\mathrm{m}}(\mathrm{n}), \mathrm{n}=0, \ldots, \mathrm{N}-1$ are orthogonal bases of linear frequency modulation periodic signal [5].

\section{B. The OFDM system based on affine fourier transform}

The system block diagram of DAFT-OFDM is shown in Fig. 1. The statistically independent and identically distributed $\mathrm{N}$ input information symbols, with zero mean , unit variance, are mapped into

$$
\mathrm{S}_{\mathrm{m}}=\sum_{\mathrm{n}=0}^{\mathrm{N}-1} \mathrm{~s}_{\mathrm{n}} \varphi_{\mathrm{m}}(\mathrm{n}), \mathrm{m}=-v, \ldots, \mathrm{N}-1
$$

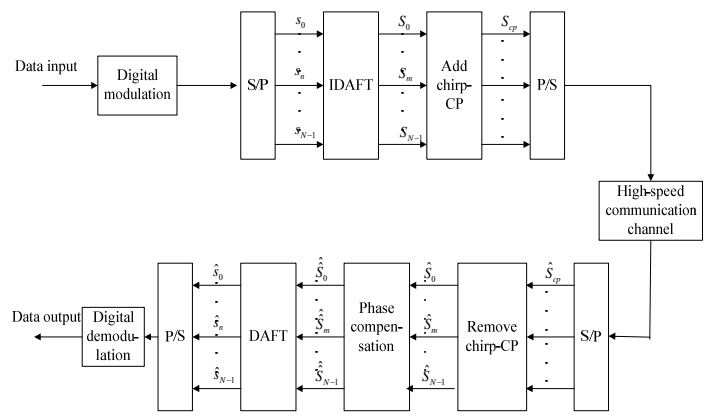

Fig..1 DAFT-OFDM system block diagram

Transmitted in the discrete time-varying channel, $\mathrm{S}_{\mathrm{m}}$ can be expressed as

$$
\widehat{\mathrm{S}}_{\mathrm{m}}=\sum_{\mathrm{\iota}=0}^{v} \mathrm{~S}_{\mathrm{m}-\iota} \mathrm{g}_{\mathrm{m}}(\mathrm{l})
$$

$\mathrm{g}_{\mathrm{m}}(\mathrm{l})$ is channel coefficient.

At the receiving end, the output symbols are obtained in turn, through extracting linear frequency modulation components.

$$
\widehat{\mathrm{s}}_{\mathrm{k}}=\sum_{\mathrm{m}=0}^{\mathrm{N}-1} \widehat{\mathrm{S}}_{\mathrm{m}} \varphi_{\mathrm{m}}^{*}(\mathrm{k})
$$

So, the relation between input signal and output signal can be written as

$$
\begin{gathered}
\hat{\mathrm{s}}_{\mathrm{k}}=\sum_{\mathrm{n}} \mathrm{h}_{\mathrm{k}, \mathrm{n}} \mathrm{s}_{\mathrm{n}} \cdot \\
\mathrm{h}_{\mathrm{k}, \mathrm{n}}=\mathrm{e}^{\mathrm{j} 2 \pi \mathrm{c}_{2}\left(\mathrm{n}^{2}-\mathrm{k}^{2}\right)} \frac{1}{\mathrm{~N}} \sum_{\mathrm{m}=0}^{\mathrm{N}-1}\left(\mathrm{e}^{-\mathrm{j} 2 \pi \frac{\mathrm{km}}{N}} \sum_{\mathrm{l}=0}^{v} v_{\mathrm{m}}(\mathrm{l}) \mathrm{e}^{\mathrm{j} 2 \pi \frac{\mathrm{n}(\mathrm{m}-\mathrm{l})}{\mathrm{N}}}\right) \\
v_{\mathrm{m}}(\mathrm{l})=\mathrm{g}_{\mathrm{m}}(\mathrm{l}) \mathrm{e}^{\mathrm{i} 2 \pi \mathrm{c}_{1} \mathrm{\iota}^{2}} \mathrm{e}^{-\mathrm{j} 2 \pi\left(2 \mathrm{c}_{1}\right) \mathrm{m} \mathrm{\iota}}
\end{gathered}
$$

Formula (5) includes the DAFT and chirp type cyclic prefix, these two part. Chirp type cyclic prefix can adapt to the instantaneous change of channel response and chirp type characteristic functions in the symbol time interval can keep orthogonality. So, in the symbol period, the relation between input signal and output signal is simple multiplication relationship[5].
To realize the good recovery of transmission signal at the receiving end, a phase compensation block is added in, after removing cyclic prefix [6]. Assuming that the phase check parameter is $\mathrm{c}_{0}$. Because formula (8) has nothing to do with $c_{2}$, so set $c_{2}=0$ [7]. At this time,

$$
g_{m}(l)=v(\iota) e^{-i 2 \pi c_{1} \iota^{2}} e^{j 2 \pi\left(2 c_{1}\right) m}
$$

Under the condition of $c_{2}=0, c_{0}, c_{1}$ are needed to be chosen according to channel characteristic [8].

\section{INTERFERENCE ANALYSIS}

\section{A. Time-varying channel interference power analysis} expression

Usually, high-speed communication channel is wide sense stationary uncorrelated scattering channe 1(WSSUS). So the corresponding scattering function can fully describe the channel[9].

$\mathrm{E}\left[\mathrm{h}(\tau, v) \mathrm{h}^{*}\left(\tau_{1}, v_{1}\right)\right]=\mathrm{S}(\tau, v) \delta\left(\tau-\tau_{1}\right) \delta\left(v-\mathrm{v}_{1}\right)$

The received signal energy $A\left(\tau_{P}, \nu_{p}\right)$ is defined as function of time delay and Doppler shift.

$$
\mathrm{A}\left(\tau_{\mathrm{P}}, v_{\mathrm{p}}\right)=\int_{-\infty}^{\infty} \mathrm{g}(\mathrm{t}) \mathrm{g}^{*}\left(\tau-\tau_{\mathrm{p}}\right) \mathrm{e}^{-\mathrm{j} 2 \pi v_{\mathrm{p}} \mathrm{t}} \mathrm{dt}
$$

$A\left(\tau_{P}, v_{p}\right)$ is a kind of linear transformation ambiguity function,

$$
\begin{gathered}
\tau_{P}=\left(n^{\prime}-n\right) T+\tau, v_{p}=\frac{1}{T}\left(k^{\prime}-k\right)+v-c_{0}- \\
2 c_{1}\left(\left(n^{\prime}-n\right) T+\tau\right)
\end{gathered}
$$

In wireless channels, $\tau \in\left[0, \tau_{\max }\right], v \in\left[-v_{d}, v_{d}\right]$. so

$$
\mathrm{P}_{\mathrm{U}}=\int_{-v_{\mathrm{d}}}^{v_{\mathrm{d}}} \int_{0}^{\tau_{\max }} \mathrm{S}(\tau, v)\left|\mathrm{A}\left(\tau_{\mathrm{P}}, v_{\mathrm{p}}\right)\right|_{\substack{\mathrm{n}=\mathrm{n}^{\prime} \\ \mathrm{k}=\mathrm{k}^{\prime}}}^{2} \mathrm{~d} \tau \mathrm{d} v
$$

The interference power of the $k$ th subcarrier at the $n$th time interval,

$$
P_{I}=\int_{-\infty}^{\infty} \int_{-\infty}^{\infty} S(\tau, v) \sum_{(n, k) \neq\left(n^{\prime}, k^{\prime}\right)}\left|A\left(\tau_{P}, v_{P}\right)\right|^{2} d \tau \mathrm{d} v
$$

\section{$B$. The interference power of the DAFT-OFDM system}

At the receiving end, the baseband signal of DAFTOFDM system is

$$
\begin{array}{r}
\mathrm{s}(\mathrm{t})= \\
\sum_{\mathrm{n}=-\infty}^{\infty} \sum_{\mathrm{k}=0}^{\mathrm{M}-1} \mathrm{~s}_{\mathrm{n}, \mathrm{k}} \mathrm{g}(\mathrm{t}-\mathrm{nT}) \mathrm{e}^{\mathrm{j} 2 \pi\left(\mathrm{c}_{1}(\mathrm{t}-\mathrm{nT})^{2}+\mathrm{c}_{2} \mathrm{k}^{2}+\frac{\mathrm{k}}{\mathrm{T}}(\mathrm{t}-\mathrm{nT})\right)}
\end{array}
$$

$\mathrm{M}$ is the number of subcarriers, $\left\{\mathrm{s}_{\mathrm{n}, \mathrm{k}}\right\}$ is the data symbol of the kth subcarrier at the nth time interval, $g(t)$ is normalized rectangular pulse waveform, $\mathbf{T}$ is symbol period. The rectangular pulse of system $\mathrm{g}(\mathrm{t})=$ $1 / \sqrt{\mathrm{T}},-\mathrm{T} / 2 \leq \mathrm{t} \leq \mathrm{T} / 2$. Usually, protection interval, with length $\mathrm{T}_{\mathrm{GI}}$, join the transmit pulse to eliminate the multipath time delay effect. When $\mathrm{n}=\mathrm{n}^{\prime}$ and $\mathrm{k}=\mathrm{k}^{\prime}$, $A\left(\tau_{P}, v_{P}\right)$ can be expressed as

$$
A\left(\tau_{P}, v_{P}\right)=\operatorname{sinc} \pi T\left(v-c_{0}-2 c_{1} \tau\right)
$$

In actual channel, both time and frequency diffusion are limited. $S(\tau, v)$ is nonzero value, when $\tau \in\left[0, \tau_{\max }\right.$ and $v \in\left[-v_{\mathrm{d}}, v_{\mathrm{d}}\right]$. Assuming that $S(\tau, v)$ is unit power, so the total powerP $P_{I}+P_{U}=1$. At this point, the interference power can be expressed as 


$$
\begin{gathered}
\mathrm{P}_{\mathrm{I}}=1-\int_{-v_{d}}^{v_{d}} \int_{0}^{\tau_{\max }} S(\tau, v) \operatorname{sinc}^{2} \pi \mathrm{T}\left(v-\mathrm{c}_{0}\right. \\
\left.-2 \mathrm{c}_{1} \tau\right) \mathrm{d} \tau \mathrm{d} v \\
\operatorname{sinc}^{2} \pi \mathrm{T}\left(v-\mathrm{c}_{0}-2 \mathrm{c}_{1} \tau\right) \\
\geq 1 \\
-1 / 3 \cdot \pi^{2} \mathrm{~T}^{2}\left(v-\mathrm{c}_{0}\right. \\
\left.-2 \mathrm{c}_{1} \tau\right)^{2}
\end{gathered}
$$

The scattering instantaneous function $\mathrm{m}_{\mathrm{i}, \mathrm{j}}\left(\mathrm{c}_{0}, \mathrm{c}_{1}\right)$ of DAFT-OFDM system, spreads surrounding the straight line $v=c_{0}+2 c_{1}$ tand $\tau$ axis, that is

$$
\begin{gathered}
\mathrm{m}_{\mathrm{i}, \mathrm{j}}\left(\mathrm{c}_{0}, \mathrm{c}_{1}\right)=\int_{-v_{\mathrm{d}}}^{v_{\mathrm{d}}} \int_{0}^{\tau_{\max }} \mathrm{S}(\tau, v)\left(v-\mathrm{c}_{0}-2 \mathrm{c}_{1} \tau\right)^{\mathrm{i}} \tau^{\mathrm{j}} \mathrm{d} \tau \mathrm{d} v \\
\mathrm{P}_{\mathrm{I}} \leq \frac{1}{3} \mathrm{~m}_{2,0}\left(\mathrm{c}_{0}, \mathrm{c}_{1}\right) \pi^{2} \mathrm{~T}^{2}
\end{gathered}
$$

$\mathrm{m}_{2,0}\left(\mathrm{c}_{0}, \mathrm{c}_{1}\right)$ is the Doppler spread. In this case, the ISI is eliminated, with ICI remained.

When $\mathrm{c}_{0}=0, \mathrm{c}_{1}=0, \mathrm{~m}_{\mathrm{i}, \mathrm{j}}(0,0)$ belongs to OFDM system. By binomial formula, $\mathrm{m}_{\mathrm{i}, \mathrm{j}}\left(\mathrm{c}_{0}, \mathrm{c}_{1}\right)$ of DAFT-OFDM can be calculated, by using $\mathrm{m}_{\mathrm{i}, \mathrm{j}}(0,0)$ of OFDM.

$$
\begin{aligned}
\mathrm{m}_{\mathrm{i}, \mathrm{j}}\left(\mathrm{c}_{0}, \mathrm{c}_{1}\right)= & \sum_{\mathrm{k}=0}^{\mathrm{i}} \sum_{\mathrm{l}=0}^{\mathrm{i}-\mathrm{k}}(-1)^{\mathrm{l}+\mathrm{k}}\left(\begin{array}{c}
\mathrm{i} \\
\mathrm{k}
\end{array}\right)\left(\begin{array}{c}
\mathrm{i}-\mathrm{k} \\
\mathrm{l}
\end{array}\right) * \\
& \mathrm{c}_{0}^{\mathrm{l}}\left(2 \mathrm{c}_{1}\right)^{\mathrm{k}} \mathrm{m}_{\mathrm{i}-\mathrm{k}-\mathrm{l}, \mathrm{k}+\mathrm{j}}(0,0)
\end{aligned}
$$

From formula (15), the interference power only depends on the Doppler spread and symbol duration time. To restrain the interference power maximally, the parameter $\mathrm{c}_{0}$ and $\mathrm{c}_{1}$ should be carefully chosen [8].

\section{AFT parameter choice}

DAFT-OFDM system can keep the interference power value low, by adjusting the parameter $c_{0}$ and $c_{1}$, according to the channel state. Usually

$$
\begin{gathered}
\mathrm{c}_{0 \text { opt }}=\frac{\mathrm{m}_{0,2}(0,0) \mathrm{m}_{1,0}(0,0)-\mathrm{m}_{0,1}(0,0) \mathrm{m}_{1,1}(0,0)}{\mathrm{m}_{0,2}(0,0)-\mathrm{m}_{0,1}^{2}(0,0)} \\
\mathrm{c}_{1 \text { opt }}=\frac{\mathrm{m}_{1,1}(0,0)-\mathrm{m}_{0,1}(0,0) \mathrm{m}_{1,0}(0,0)}{2\left(\mathrm{~m}_{0,2}(0,0)-\mathrm{m}_{0,1}^{2}(0,0)\right)} \\
\mathrm{m}_{0,1}(0,0)=1 / \mathrm{k}+\tau_{\mathrm{diff}}, \mathrm{m}_{1,0}(0,0)=\frac{\mathrm{k}}{\mathrm{k}+1} v_{\mathrm{LOS}}+ \\
\frac{1}{\mathrm{k}+1} \alpha_{1}, \mathrm{~m}_{0,2}(0,0)=\frac{1}{\mathrm{k}+1} \tau_{\mathrm{diff}}^{2}, \mathrm{~m}_{2,0}(0,0)=\frac{\mathrm{k}}{\mathrm{k}+1} v_{\mathrm{LOS}}^{2}+ \\
\frac{1}{\mathrm{k}+1} \alpha_{2}, \alpha_{1}=\int_{-v_{\mathrm{d}}}^{v_{\mathrm{d}}} \mathrm{P}_{\text {diff }}(v) v^{\mathrm{i}} \mathrm{d} v .
\end{gathered}
$$

To simplify the expression of scattering instantaneous function,

$$
\alpha_{1}=c_{g}\left[\frac{v_{\mathrm{x}}}{c_{\mathrm{g}}}\right], \alpha_{2}=\mathrm{c}_{\mathrm{g}}\left[\frac{\mathrm{B}_{\mathrm{RMS}}^{2}}{4 \mathrm{c}_{\mathrm{g}}}+\frac{v_{\mathrm{x}}^{2}}{\mathrm{c}_{\mathrm{g}}}-\frac{\mathrm{B}_{\mathrm{RMS}} \Delta \operatorname{vexp}\left(-\frac{2 \Delta v^{2}}{\mathrm{~B}_{\mathrm{RMS}}^{2}}\right)}{\sqrt{2}}\right]
$$

The multipath channel characterized by scattering function can be defined as [9]

$$
\mathrm{S}(\tau, v)=\frac{\mathrm{k}}{\mathrm{k}+1} \delta(\tau) \delta\left(\nu-v_{\mathrm{LOS}}\right)+\frac{1}{\mathrm{k}+1} \mathrm{P}_{\text {diff }}(v) \delta\left(\tau-\tau_{\text {diff }}\right)
$$

$\mathrm{P}_{\text {diff }}(v)$ represents for the doppler power distribution function, $\tau_{\text {diff }}$ is the aximum time delay, $k$ is Rician factor, $k=1$ represents for no channel coding.

Doppler power distribution function can be modeled as a gaussian model,
$\mathrm{P}_{\text {diff }}(v)=c_{\mathrm{g}} \frac{\sqrt{2}}{\mathrm{~B}_{\mathrm{RMS} \sqrt{\pi}}} \exp \left(-\frac{2\left(v-v_{\mathrm{X}}\right)^{2}}{\mathrm{~B}_{\mathrm{RMS}}^{2}}\right), v_{1} \leq v \leq v_{2}$

$c_{g}=1 / \operatorname{Erf}\left(1.41 \Delta v / B_{r m s}\right)$ is normalized factor.

$\mathrm{B}_{\mathrm{RMS}}$ is root-mean-square of Doppler spread, $\mathrm{B}_{\mathrm{RMS}}=$ $4 \varepsilon f_{c} / c \cdot v \sin (\alpha)$.

The $a$ is root-mean-square of ground slope, $a$ is inclined angle between the signal direction and the driving direction of high-speed running vehicle, $v$ is velocity vector, $\mathrm{f}_{\mathrm{c}}$ is carrier frequency, $\mathrm{c}$ is light speed, parameter $v_{1}$ and $v_{2}$ can be calculated by $v_{i}=$ $\mathrm{vf}_{\mathrm{c}} / \mathrm{c} \cos \left(\beta_{\mathrm{i}}\right)$.

$\beta_{i}$ is inclined angle between diffusion component and velocity vector of the high-speed vehicle.

\section{Interference power comparison between DAFT-} OFDM and OFDM system

High-speed channel parameters are $\alpha=50, \beta_{1}=90^{\circ}, \beta_{2}=45^{\circ}, \varepsilon=0.04, \tau_{\text {diff }}=$ $11.5 \mu \mathrm{s}, \mathrm{f}_{\mathrm{c}}=1.55 \mathrm{GHz}, \mathrm{v}=100 \mathrm{~m} / \mathrm{s}$.

From Fig. 2, compared with OFDM system, the interference power of DAFT-OFDM system is smaller. DAFT-OFDM has strong performance of antijamming.

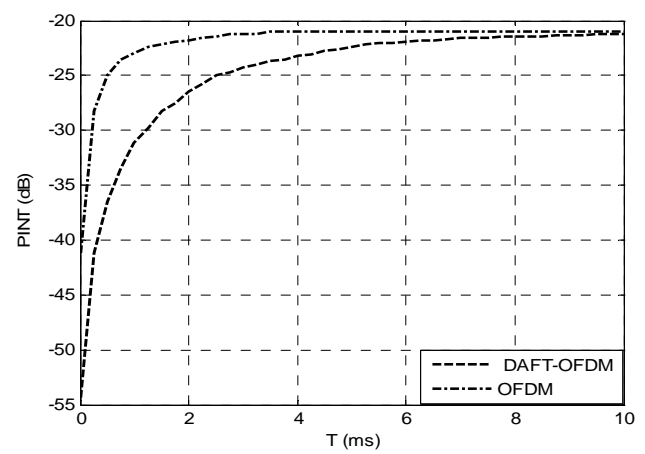

Fig. 2 The interference power of DAFT-OFDM and OFDM system

\section{The Main Performance Analysis of AfFine FOURIER TRANSFORM SYSTEM}

\section{A. Spectral efficiency}

Spectrum efficiency is an important aspect of wireless communication system. In OFDM system, subcarriers can use different modulation scheme, and each subcarrier can choose optimal modulation scheme, according to channel condition. OFDM technology, as adaptive modulation technology, when sub-channel condition is bad, uses loworder modulation scheme, such as BPSK. Otherwise, OFDM uses high-order modulation scheme. While, highspeed communication channel condition is very poorer. For OFDM, sub-carrier can only adopt the low-order modulation scheme, whereas, for DAFT-OFDM, subcarrier can adopt high-order modulation scheme, since DAFT-OFDM has the ability to suppress some interference. So DAFT-OFDM system has higher spectral efficiency. Spectral frequency of DAFT-OFDM is 


$$
\eta=1 /\left(1+T_{\mathrm{cp}} \pi \sqrt{\frac{m_{2,0}\left(c_{0}, c_{1}\right)}{\left(3 P_{\text {INT }}\right)}}\right)
$$

\section{B. Bit rate}

The subcarriers of DAFT-OFDM can use 16 QAM or 64 QAM, thus bit rate

$$
R=N \log _{2}^{M} k \pi \sqrt{\frac{m_{2,0}\left(c_{0}, c_{1}\right)}{\left(3 P_{\text {INT }}\right)}}
$$

$\mathrm{N}$ is the number of subcarrier, $\mathrm{M}$ is the number of symbols on modulation constellation. Therefore, for some $\mathrm{P}_{\mathrm{INT}}$, the bit rate can be calculated through the channel parameter $m_{2,0}\left(c_{0}, c_{1}\right)$. Fig. 3 shows the achieved bit rate for LTE system. $\mathrm{T}=66.7 \mathrm{us}, \mathrm{T}_{\mathrm{cp}}=4.7 \mathrm{us}$, and subcarrier interval of $15 \mathrm{kHz}$.Due to DAFT-OFDM has the ability of anti-interference, subcarriers can use higher-order modulation method when channel environment is poor. Thus system has higher bit rate.

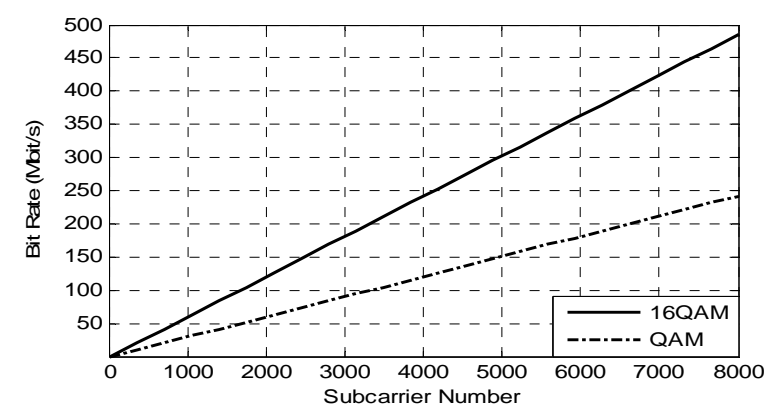

Fig..3 The achieved data rates in LTE system

\section{Bit error rate}

When $\mathrm{k}=1$ and all subcarrier adopt the QAM or 16 QAM modulation method, for some SINR(Signal to Interference and Noise Ratio), the calculation method of bit error rate for DAFT- OFDM system is

$$
\begin{gathered}
\mathrm{BER}_{\mathrm{QAM}}=\frac{1}{2} \mathrm{Q}(\sqrt{\mathrm{SINR}}), \\
\mathrm{BER}_{16 \mathrm{QAM}}=\frac{3}{4} \mathrm{Q}\left[\sqrt{\frac{1}{5} \mathrm{SINR}}\right]\left[1-\frac{3}{4} \mathrm{Q}\left[\sqrt{\left.\frac{1}{5} \mathrm{SINR}\right)}\right]\right] \\
\operatorname{SINR}=\frac{\mathrm{E}_{\mathrm{S}}}{\mathrm{N}_{0}} \cdot\left(1-\mathrm{P}_{\mathrm{INT}}\right) /\left(\frac{\mathrm{E}_{S}}{\mathrm{~N}_{0}} \mathrm{P}_{\mathrm{INT}}+1\right), \mathrm{E}_{\mathrm{S}} \text { is average }
\end{gathered}
$$
symbol energy, $N_{0}$ is noise power density.

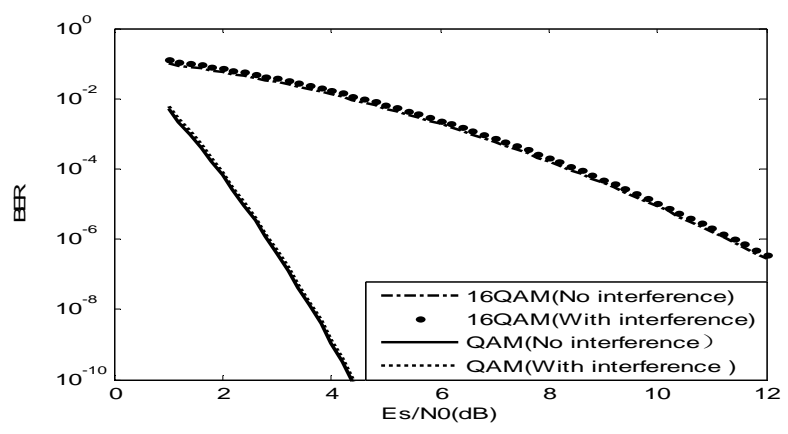

Fig..4 Bit Error Rate curves
The BER curve of Fig. 4 is obtained for $\mathrm{P}_{\mathrm{INT}}=-30 \mathrm{~dB}$ and no interference power. It is easy to know, BER deterioration caused by the Doppler spread, is negligible.

\section{CONCLUSIONS}

Compared with traditional OFDM system, OFDM system based on affine fourier transform can effectively suppress ICI caused by the Doppler effect, and has high spectral efficiency, high bit rate and low bit error rate. In a word, DAFT-OFDM system can effectively restrain ICI of the time-frequency double selective channel and can keep good communication quality in high-speed mobile environment.

\section{REFERENCES}

[1] Chengguo Liu, Yu Zhao, Jing Zhou. Modelling on the Signal BER of Communication System for High-speed Railway [C]//IEEE IRI 2012. Las Vegas, Nevada, USA: IEEE, 2012.1255-1259.

[2] WANG Yi-lin, CHEN Yun, YIN Jing-wei. Research on orthogonal multi-carrier underwater acoustic communication system based on fractional Fourier transfrom [J]. Journal on Communications, 2012, 33(8): 162-170

[3] WANG Hui-qi, and MA Hong. The MIMO-OFDM System Based on the Optimal Fractional Fourier Transform[J], JOURNAL OF SICHUAN UNIVERSITY (EGNEERING SCIENCE EDITION), 2009, 41(6):231-236.

[4] LI Juan, and ZHAO Li. A study on Intercarrier Interference Suppression Algorithm in OFDM Systems[J], Computer Simulation, 2010, 27(2):157-161.

[5] TOMASO ERSEGHE, NICOLA LAURENTI, VALENTINA CELLINI. A Multicarrier Architecture Based Upon the Affine Fourier Transform[J]. IEEE TRANSACTIONS ON COMMUNICATIONS, Vol.53(5):853-862, May 2005.

[6] DJURO STOJANOVIC, IGOR DJUROVIC, BRANIMIR R. Interference Analysis of Multicarrier System Based on Affine Fourier Transform[J]. IEEE TRANSACTIONS ON WIRELESS COMMUNICATIONS, Vol.8(6):2877-2880,June 2009.

[7] Soo-Chang Pei, Jian-Jiun Ding. Closed-Form Discrete Fractional and Affine Fourier Transforms[J]. IEEE TRANSACTIONS ON SIGNAL PROCESSING,Vol48(5):1338-1353,May 2000.

[8] ALEN PELINKOVIC, SLOBODAN DJUKANOVIC, DJURO STOJANOVIC. A New Multicarrier System for Satellite Based Communications in the Railway Environment[C]//Mediterranean Conference on Embedded Computing. Bar Montenegro:MECO,2012. (No page numbers)

[9] S.BARVAROSSA and R.TORTI, "Chirped-OFDM for transmissions over time-varying channels with Linear delayDoppler spreading," In Pro IEEE ICASSP'01 Salt Lake City, vol.4, May 2001, pp.2377-2380 